\title{
The Effect of Mild Hearing Impairment on Auditory Processing Tests
}

\author{
Karin Neijenhuis* \\ Hans Tschur ${ }^{\dagger}$ \\ Ad Snik*
}

\begin{abstract}
The application of auditory processing tests to patients with sensorineural hearing loss is controversial. Several studies have shown that it is difficult to separate peripheral from central hearing processes. In the present study, a Dutch auditory processing test battery was administered to 24 subjects with mild, relatively flat, symmetrical sensorineural hearing loss. Tests were administered twice; the second time, the presentation level in four out of the six tests was adjusted according to the speech reception threshold. The scores of the hearing-impaired subjects were significantly poorer than those of the subjects with normal hearing on five out of the six tests, even with the adjusted presentation level. Significant correlations were found between test scores and PTA (pure-tone average); scores on words-in-noise, filtered-speech and binaural-fusion tests were additionally corrected according to PTA. In contrast to previous studies in the literature, the present dichotic-digit and patternrecognition tests were greatly influenced by mild hearing loss. Therefore, this auditory processing test battery cannot readily be used to diagnose central auditory processing disorders in patients with flat sensorineural hearing loss. At least, both adjustment of presentation level and additional correction are needed.
\end{abstract}

Key Words: Adults, auditory processing disorders, presentation level, sensorineural hearing loss

Abbreviations: APD = Auditory processing disorder; PTA = pure-tone average; SRT = speech reception threshold

\begin{abstract}
Sumario
La administración de pruebas de procesamiento auditivo a pacientes con trastornos auditivos sensorineurales es controversial. Varios estudios han mostrado que es difícil separar los procesos auditivos periféricos de los centrales. En el presente estudio, se administró una batería holandesa de pruebas de procesamiento auditivo a 24 sujetos, portadores de una hipoacusia sensorineural leve, simétrica y relativamente plana. Las pruebas se aplicaron dos veces; en la segunda vez, el nivel de presentación en cuatro de las seis pruebas se ajustó de acuerdo al umbral de recepción del lenguaje. Los puntajes de los sujetos hipoacúsicos fueron significativamente peores que aquellos de los sujetos con audición normal en cinco de las seis pruebas, aún con los niveles ajustados de presentación. Se encontraron correlaciones significativas entre los puntajes de las pruebas y el PTA (promedio tonal puro). Los
\end{abstract}

*University Medical Centre Nijmegen, Department of Otorhinolaryngology; ${ }^{\dagger}$ Institute St. Marie, Audiological Centre Eindhoven 
puntajes con palabras en ruido, con lenguaje filtrado y con pruebas de fusión binaural fueron también corregidos de acuerdo al PTA. En contraste con estudios previos en la literatura, las hipoacusias leves influyeron importantemente en las presentes pruebas de dígitos dicóticos y de reconocimiento de patrones. Por lo tanto, esta batería de pruebas de procesamiento auditivo no puede ser utilizada para diagnosticar trastornos centrales de procesamiento auditivo en pacientes con trastornos auditivos sensorineurales de perfil plano. Al menos, se requieren ajustes en el nivel de presentación y correcciones adicionales.

Palabras Clave: Adultos, trastornos de procesamiento auditivo, nivel de presentación, hipoacusia sensorineural

Abreviaturas: APD = trastornos de procesamiento auditivo, $\mathrm{PTA}=$ promedio tonal puro, SRT = umbral de reconocimiento del lenguaje

A uditory processing disorders (APDs) are defined as speech perception deficits despite normal peripheral hearing (ASHA, 1996; Jerger and Musiek, 2000). Several test batteries are available to diagnose APDs in subjects with normal hearing (Noffsinger et al, 1994; Keith, 2000; Neijenhuis et al, 2001). However, normative values for subjects with mild hearing impairment are lacking. Likewise, current consensus documents about APD (ASHA, 1996; Jerger and Musiek, 2000) associate these disorders with normal peripheral hearing. However, it is acknowledged that they may coexist with peripheral hearing loss or could be a result of conductive hearing loss (ASHA, 1996).

Some suggestions on the assessment of APDs in the presence of hearing impairment were found in the literature. First, results on auditory processing tests always have to be related to the basic audiological assessment: if test results do not correspond with expectations based on peripheral audiological assessment, it is likely that there are auditory processing disorders, in addition to peripheral auditory disorders (Miltenberger et al, 1978). Second, interpretation of auditory processing test results of hearing-impaired subjects needs to be based on ear differences (Musiek and Lamb, 1994). In the case of symmetrical hearing thresholds, auditory processing test results should also be symmetrical. If the hearing thresholds are asymmetrical and performance in the better ear is poorer than in the other ear, then an APD could be present (ASHA, 1996).
Peripheral hearing loss does not have uniform effects on the results of APD tests. Studies have shown that cochlear lesions can be clearly distinguished from cerebral lesions by the dichotic-digit test, dichotic sentence identification test, and frequency-pattern test (Fifer et al, 1983; Musiek, 1999), whereas a less clear distinction can be made using low-pass filtered speech (Chermak and Musiek, 1997), binaural interaction, and localization/lateralization (Bellis, 1996).

Several studies have shown that in patients with cochlear hearing loss of up to about $45-50 \mathrm{~dB} \mathrm{HL}$, speech perception is mainly influenced by audibility (Fifer et al, 1983; Moore, 1996). In cases with more severe loss, poor discrimination of suprathreshold stimuli plays an important role in addition to the loss of audibility. Therefore, in order to compare patients with mild hearing loss to subjects with normal hearing, it seems reasonable to simply adjust the stimulus presentation level when administering auditory processing tests.

The aim of the present study was to investigate the application of our Nijmegen APD test battery to mildly hearing-impaired patients. The following questions were addressed:

- Which test scores on the APD test battery were influenced by sensorineural hearing loss?

- Could the peripheral hearing loss be compensated for by increasing the presentation level? 


\section{METHOD}

\section{Subjects}

Subjects were recruited from the population of patients referred to our audiological center because of mild sensorineural hearing loss. In most cases, hearing aids were not (yet) being considered. The audiograms of these patients were relatively flat and symmetrical (see Fig 1 ); the slopes (i.e., difference between $4000 \mathrm{~Hz}$ and $500 \mathrm{~Hz}$ threshold) did not exceed $20 \mathrm{~dB}$ in either ear. We selected 24 cases with relatively flat audiograms, because their hearing loss could be compensated for by increasing the presentation level across all the frequencies. Their PTA (pure-tone average) (500-4000 $\mathrm{Hz}$ ) ranged from 17.5 to $37.5 \mathrm{~dB} \mathrm{HL}$ and was equal in both ears to within $5 \mathrm{~dB}$. A maximum difference of $5 \mathrm{~dB}$ between bone- and airconduction PTAs (air-bone gaps) was allowed. All the eligible subjects had a maximum speech recognition score (monosyllables) of $100 \%$. Mean speech reception thresholds (SRT both ears) ranged from 18 to $36 \mathrm{~dB}$; this was in accordance with the PTA range. Tone and speech audiometric data, eventually supplemented with tympanometry and reflex measurements, were used to exclude middleear pathology or possible retrocochlear disorders.
The mean age of the 24 hearing-impaired subjects was 54 years (range 38 to 69 years). Control subjects $(\mathrm{n}=30)$ had normal peripheral hearing (PTA [500-4000 Hz] ranging from -1 to $15 \mathrm{~dB} \mathrm{HL}$ ) and no complaints about speech perception. The mean age of the control subjects was 40 years (range 25 to 67 years).

\section{Materials}

After standard audiometric testing (pure tone and speech audiometry), a test battery for auditory processing disorders (Neijenhuis et al, 2001) was administered in a separate session. The test battery comprised six different tests: sentences-in-noise test, pattern-recognition test, words-in-noise test, dichotic-digit test, filtered-speech test, and binaural-fusion test.

\section{Sentences-in-Noise Test}

This test was developed by Plomp and Mimpen (1979) and measures the speech reception threshold (SRT) for sentences in noise. The sentences consist of eight or nine syllables and avoid words of more than three syllables. Three sets of 13 sentences are used: one set to familiarize the subjects with the task (presenting the sentences in quiet), one set in continuous noise, and one set in fluctuating noise. Items were presented

\section{right ear}

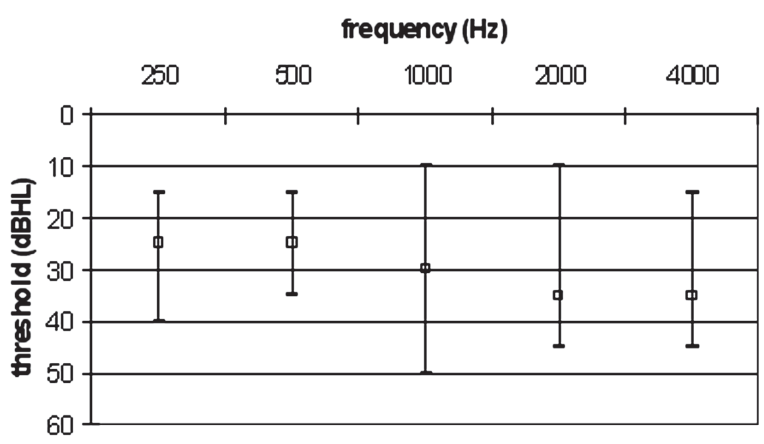

\section{left ear}

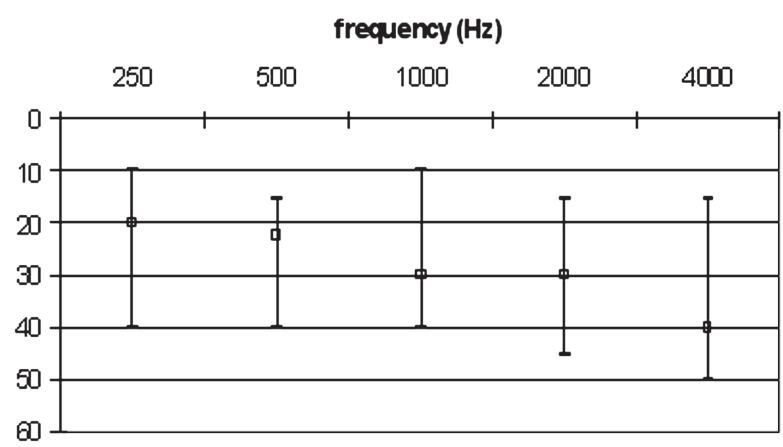

Figure 1. Pure-tone thresholds of 24 hearing-impaired subjects in the present study. The group audiogram shows median, minimum, and maximum pure-tone thresholds. Bone-conduction thresholds were equal to air-conduction thresholds. 
monaurally, to the right ear. The subjects were asked to repeat the sentences verbatim. The level of noise was kept constant ( $65 \mathrm{~dB}$ SPL), while the level of the sentences was adjusted according to a one-up, one-down adaptive procedure using a step size of $2 \mathrm{~dB}$ (Plomp and Mimpen, 1979). Signal-to-noise ratios $(\mathrm{S} / \mathrm{N})$ were calculated for the continuous noise and fluctuating noise conditions.

\section{Frequency-and Duration-Pattern Tests}

Two tests, developed by Pinheiro and Ptacek (1971) and Musiek (1994), were used to address temporal processing of nonverbal stimuli. Material was copied from the compact disc "Tonal and Speech Materials for Auditory Perceptual Assessment" (Noffsinger et al, 1994). Subjects were required to describe sequences of three pure tones, in which one tone had a different frequency or duration from the other two (e.g., "high-low-high" in the frequency-pattern test and "long-shortlong" in the duration-pattern test). In the frequency-pattern test, the "low" and "high" tones had frequencies of $880 \mathrm{~Hz}$ and $1122 \mathrm{~Hz}$; the tones were $150 \mathrm{msec}$ long, while the interval between them was $200 \mathrm{msec}$. In the duration-pattern test, all the tones had a frequency of $1000 \mathrm{~Hz}$; the "short" and "long" tones had a duration of $250 \mathrm{msec}$ and 500 msec, while the interval between them was 300 msec. The interval between the patterns was $6 \mathrm{sec}$. Presentation level was $60 \mathrm{~dB}$ SPL, and the sequences were presented diotically. To keep the total testing time to a minimum, 10 practice items and 30 test items were selected. In the two tests, the score was the percentage of correctly reproduced sequences.

\section{Words-in-Noise Test}

Monosyllables (Bosman, 1989; Bosman and Smoorenburg, 1992) were presented to the right ear and left ear separately. The speech noise, with the same spectrum as the words, was presented to the test ear at a fixed level of $65 \mathrm{~dB}$ SPL but was interrupted between words to avoid adaptation to the noise. A signal-to-noise ratio $(\mathrm{S} / \mathrm{N})$ of $-2 \mathrm{~dB}$ was used. Before administration of the four test lists, another list was presented at an $\mathrm{S} / \mathrm{N}$ of $0 \mathrm{~dB}$ as a practice list (12 words). Each list (22 words) was always presented using the same $\mathrm{S} / \mathrm{N}$, and the presentation order was fixed. The percentage of correctly reproduced phonemes determined the score in the left ear or right ear.

\section{Dichotic-Digits Test}

Max and D'Haese (1994; Max 1995) developed a Dutch version of this test (Kimura, 1961). The speech material consisted of five practice items and 20 test items. Each item contained six one-syllable digits. Three digits were presented to one ear, while three other digits were presented simultaneously to the other ear. The subject was asked to repeat as many digits as possible (free recall). Presentation level was $70 \mathrm{~dB}$ SPL. Percentage correct scores were computed for each ear separately and for both ears together.

\section{Filtered-Speech Test}

The word material (also from Bosman and Smoorenburg, 1992) was filtered by using a low-pass filter with a cutoff frequency of 500 $\mathrm{Hz}$ and a high-pass filter with a cutoff frequency of $3 \mathrm{kHz}$, both with a slope of 60 $\mathrm{dB} /$ octave. The presentation level was $65 \mathrm{~dB}$ SPL after filtering. Both the low- and the high-frequency bands were presented monaurally. Before administration of the two test lists ( 22 words), another list was presented as a practice list (12 words). The percentage of correctly reproduced phonemes determined the score in each ear.

\section{Binaural-Fusion Test}

In the binaural-fusion test, the same filtering was used as in the filtered-speech test, but the low-pass filtered speech was presented to one ear, while the high-pass filtered speech was presented to the other (Matzker, 1959; Bornstein et al, 1994). One list of 22 monosyllables was used: for the first 11 words, the low-pass speech was presented to the right ear, while for the last 11 words, the high-pass speech was presented to the right ear. The percentage of correctly reproduced phonemes determined the score.

\section{Procedure}

Tests were administered to all the participants with the aid of a compact disc player, clinical audiometer (AC40), and headphones (TDH-39). The auditory 
Table 1. Description of the Order in Which the Test Battery Was Administered to Hearing-Impaired Subjects

\begin{tabular}{lll}
\hline Test & Subtest & Presentation level \\
\hline 1. Sentences-in-noise test & $\begin{array}{l}\text { Continuous noise } \\
\text { Fluctuating noise }\end{array}$ & Normal level (65 dB SPL) \\
\hline 2. Sentences-in-noise test & $\begin{array}{l}\text { Continuous noise } \\
\text { Fluctuating noise }\end{array}$ & Adjusted level \\
\hline 3. Filtered-speech test & Right ear & Normal level (65 dB SPL) \\
\hline 4. Binaural-fusion test & Left ear & \\
\hline 5. Words-in-noise test & Both ears & Normal level (65 dB SPL) \\
\hline 6. Pattern-recognition tests* & Right ear, -2 dB & Normal level (65 dB SPL) \\
& Left ear, -2 dB & \\
\hline 7. Words-in-noise test & & Normal level (60 dB SPL) \\
\hline 8. Dichotic-digit test* & Frequency patterns & \\
\hline 9. Filtered-speech test & Duration patterns & Adjusted level \\
\hline 10. Binaural-fusion test & Right ear, -2 dB & \\
\hline Left ear, -2 dB & Both ears & Normal level (70 dB SPL) \\
\hline
\end{tabular}

Note: Tests indicated with an asterisk were administrated at normal presentation level only. The adjusted presentation level was calculated by dividing the SRT by two and adding this to the normal presentation level.

processing tests were administered in a fixed order (see Table 1). The order of the tests was chosen such that there was enough variation between verbal and nonverbal tests and between tests with and without noise. Subjects were encouraged to guess an answer if they were not sure. The full testing session took 120 minutes, including a coffee break.

All six tests were administered to the control subjects at a standard ("normal") presentation level (see Table 1). In the hearing-impaired subjects, all six tests were first administered at the normal presentation level. Then four tests were repeated at a presentation level that was increased according to the patient's hearing loss: the sentences-in-noise test, words-in-noise test, filtered-speech test, and binaural-fusion test. To determine the amount of adjustment required, the principle of the one half-gain rule (see, e.g., Schwartz et al, 1988) was applied: the presentation level was increased by half the speech reception threshold (SRT). With the gain equal to half the hearing loss, the most comfortable listening levels of the hearing-impaired subject will be comparable to those of normal-hearing subjects. The required adjustment varied from 9 to $18 \mathrm{~dB}$, resulting in 10,15 , or $20 \mathrm{~dB}$ increase of presentation level.

The dichotic-digit test and the pattern tests were not administered at an adjusted presentation level, because other studies have shown that the results of these tests are not influenced by mild sensorineural hearing loss (Speaks et al, 1985; Musiek and Pinheiro, 1987; Musiek et al, 1990).

\section{RESULTS}

\section{Comparison between the Normative Group and the Hearing-Impaired Group}

Group differences between hearingimpaired and control subjects were statistically analyzed using Mann-Whitney nonparametric tests. Hearing-impaired subjects' scores were significantly lower than control subjects' scores when the test stimuli were presented at the normal presentation level (see Figures 2, 3, and 4). This significant difference was found in all six tests. Some 


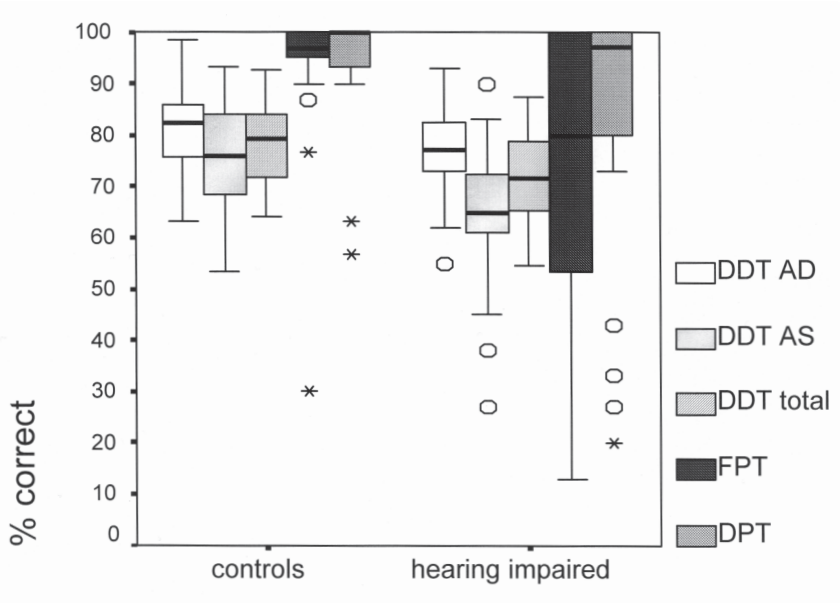

Figure 2. Boxplots showing scores on two tests: dichotic-digit test (DDT) and pattern-recognition tests (frequency patterns [FPT], duration patterns [DPT]). Scores of control subjects were compared to those of 24 hearing-impaired subjects. Tests were administered at normal presentation level. The boxes represent scores of $50 \%$ of the subjects, with the bold black line showing the median. Outliers (displayed as "o") are between 1.5 box lengths and 3 box lengths from the end of the box. Extremes (displayed as "*") are more than 3 box lengths from the end of the box.

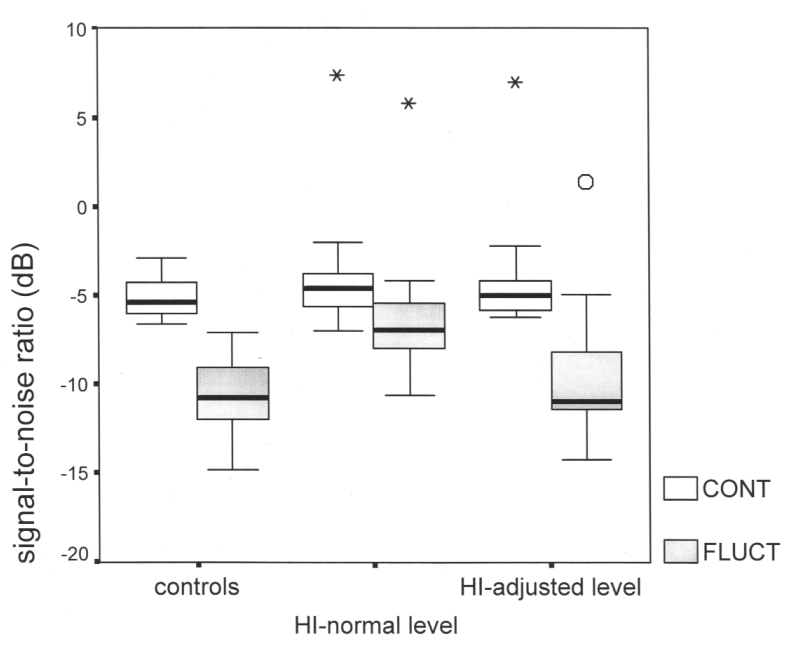

Figure 4. Boxplots indicating scores on the sentencesin-noise tests: continuous noise condition (CONT) and fluctuating noise condition (FLUCT). Scores of the control group were compared to those of the hearing-impaired (HI) normal presentation level and hearing-impaired (HI) adjusted presentation level.

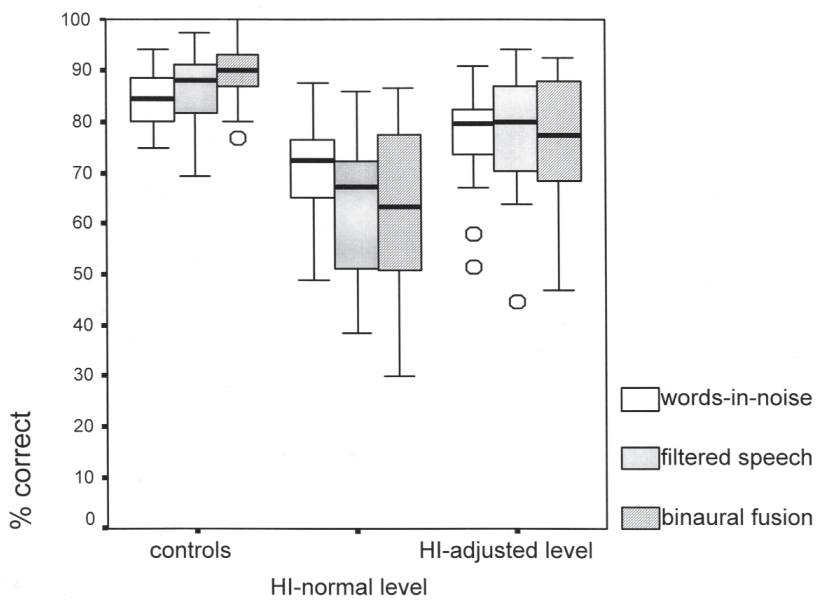

Figure 3. Boxplots indicating scores on three tests: words-in-noise (mean score), filtered speech (mean score), and binaural fusion. Scores of the control group were compared to those of the hearing-impaired (HI) normal presentation level and hearing-impaired (HI) adjusted presentation level.

subscores did not show any significant difference between the two groups: sentences in continuous noise $(\mathrm{p}=0.25)$, duration pattern recognition $(p=0.20)$, dichotic-digits right ear score $(\mathrm{p}=0.33)$ and dichotic-digits total score $(p=0.08)$.

Four tests were administered to the hearing-impaired subjects at two different presentation levels. At the adjusted level, several test scores were still significantly lower than those of the control group (see Figures 3 and 4). Subscores that did not show any significant differences after the adjustment were the sentences-in-noise test (continuous noise $[p=0.46]$ and fluctuating noise $[\mathrm{p}=0.55])$ and filtered-speech, right ear score $(\mathrm{p}=0.17)$.

\section{Within-Subject Effects of Correcting the Presentation Level}

In all the tests, except for the subtest sentences in continuous noise, the scores at the adjusted presentation level were significantly better than those at the normal 

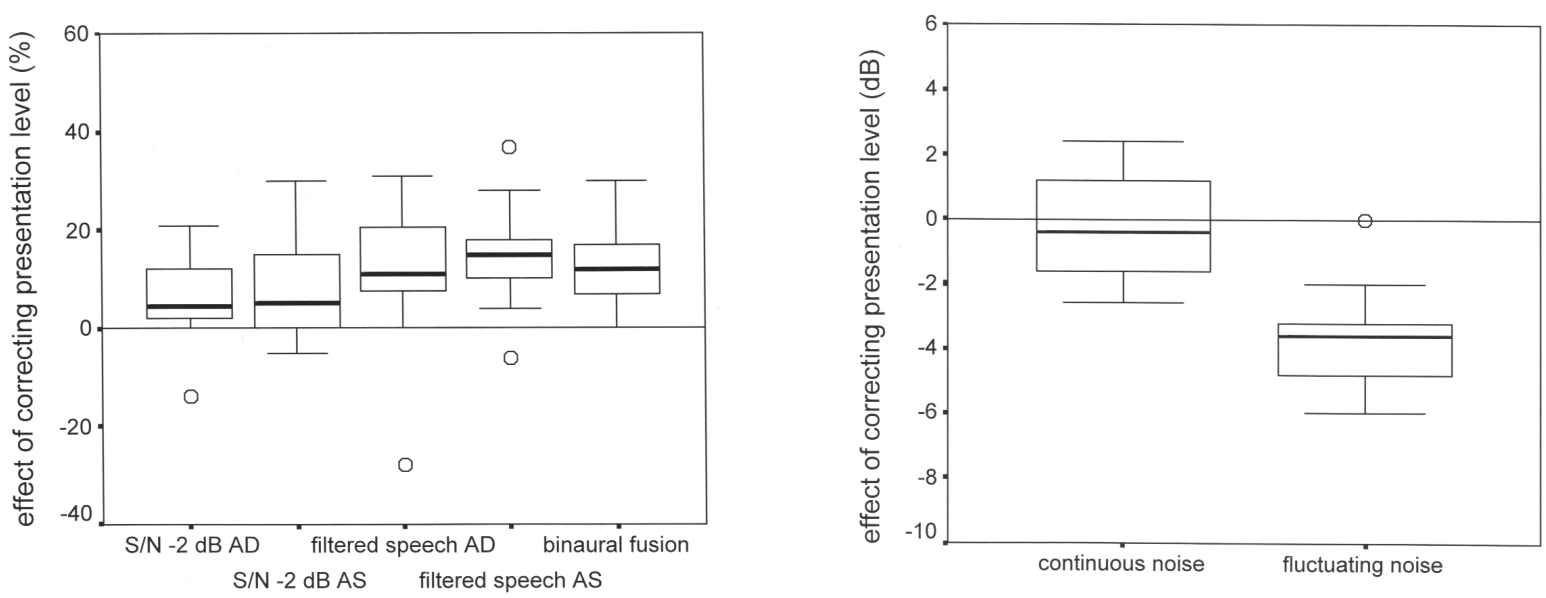

Figure 5. Boxplots showing the increase in scores on four different tests: words-in-noise (SN-2), filtered speech, binaural fusion, and sentences-in-noise. Scores with the initial presentation level were subtracted from scores with the adjusted presentation level. A \% score of above 0 indicates a positive effect of adjusting the presentation level, except for the sentences-in-noise test, where scores were computed as signal-to-noise ratios (dB). A score of below 0 on this test indicated a positive effect of $\mathrm{dB}$ adjustment.

level. This was confirmed by t-tests for comparison with zero $(\mathrm{p}<0.01)$, which suggests that corrections regarding audibility are useful.

\section{Percentile Scores}

In a previous article (Neijenhuis et al, 2003), percentile scores were applied to facilitate the interpretation of auditory processing test scores. For each subtest, the 10th percentile of the control group was taken as the cutoff score; scores of below the 10th percentile were considered to be abnormal.

Using this criterion, it was found that the percentage of abnormal scores was rather high for most subtests, especially concerning filtered speech and words-in-noise (see Table 2 ). After adjusting the presentation level, the rates decreased. However, approximately $25 \%$ of the patients still had scores that reflected disorders.

Table 2. Percentage of Hearing-Impaired Subjects Who Scored Below the 10th Percentile, Computed for Each Subtest

\begin{tabular}{|c|c|c|c|c|}
\hline \multirow[t]{2}{*}{ Test } & \multirow[t]{2}{*}{ Subtest } & \multicolumn{3}{|c|}{$\%$ deviant scores } \\
\hline & & Initial level & $\begin{array}{l}\text { Adjusted } \\
\text { level }\end{array}$ & $\begin{array}{l}\text { Additional } \\
\text { correction }\end{array}$ \\
\hline Sentences-in-noise test & $\begin{array}{l}\text { Continuous noise } \\
\text { Fluctuating noise }\end{array}$ & $\begin{array}{l}25 \% \\
73 \%\end{array}$ & $\begin{array}{l}23 \% \\
29 \%\end{array}$ & \\
\hline Pattern-recognition tests & $\begin{array}{l}\text { Frequency patterns } \\
\text { Duration patterns }\end{array}$ & $\begin{array}{l}42 \% \\
25 \%\end{array}$ & & \\
\hline Words-in-noise test & Mean score, $-2 \mathrm{~dB}$ & $71 \%$ & $27 \%$ & $0 \%$ \\
\hline Dichotic-digit test & $\begin{array}{l}\text { Right ear } \\
\text { Left ear } \\
\text { Both ears }\end{array}$ & $\begin{array}{l}9 \% \\
17 \% \\
22 \%\end{array}$ & & \\
\hline Filtered-speech test & Mean score & $58 \%$ & $24 \%$ & $5 \%$ \\
\hline Binaural-fusion test & Both ears & $46 \%$ & $10 \%$ & $5 \%$ \\
\hline
\end{tabular}

Note: Deviant scores were evaluated in three situations: (1) administration of the tests at the standard normal (initial) presentation level, (2) administration of the tests at the adjusted presentation level, (3) administration at adjusted level and additional correction of score according to the PTA. 


\section{Ear Differences}

For three tests (words-in-noise, filteredspeech and dichotic-digit test), ear difference scores were computed by subtracting the left ear score from the right ear score. Ear differences in the hearing-impaired subjects (both at normal and adjusted presentation levels) were not significantly different from those found in the control group.

\section{Effect of Hearing Loss on Test Scores}

Pearson's correlations were used to compare peripheral hearing test scores (taken from pure-tone and speech audiometry) to test scores on auditory processing tests at the adjusted presentation level (for sentences-in-noise, words-in-noise, filtered-speech, and binaural-fusion tests) and the normal presentation level (for dichotic-digit and pattern-recognition test). Word-recognition scores at $65 \mathrm{~dB}$ correlated significantly with filtered-speech $(r=0.68)$ and binaural-fusion scores $(\mathrm{r}=0.58)$, as well as with the words-in-noise score $(r=0.45)$. No significant correlations were found with the SRT. In the group of hearing-impaired subjects, the mean PTA (500-4000 Hz) was not significantly correlated with any auditory processing test scores. However, when the subjects with normal hearing were combined with the hearing-impaired subjects, the PTA correlated significantly with all the test scores, except for sentences in noise, duration patterns and dichotic digits (right ear and total score). This means that it may be possible to correct test scores according to the mean PTA. Therefore, linear regression analyses were used to make additional corrections to the words-in-noise, filteredspeech, and binaural-fusion test scores. In comparing these additionally corrected scores to both the 10th and the 25th percentile of the control group, the percentage of abnormal scores significantly reduced (see Table 2). On the binaural-fusion test, however, still $48 \%$ of the hearing-impaired subjects scored below the 25 th percentile, which is not entirely satisfactory.

\section{DISCUSSION}

$\mathrm{T}$ he present study addressed the effect of mild hearing impairment on tests for auditory processing, in order to develop a protocol for diagnosing auditory processing disorders in hearing-impaired subjects. Six auditory processing tests were administered to 24 subjects with mild hearing impairment. Four of these tests were administered at two presentation levels: the normal level and a level that was adjusted according to the patient's speech reception threshold (SRT).

\section{Effect of Mild Hearing Impairment on Test Scores}

In hearing-impaired subjects, scores on all six auditory processing tests were significantly poorer than those in the control subjects, except for ear difference scores that were in the normal range. Despite adjustment of the presentation level, scores on words-innoise, filtered-speech, and binaural-fusion tests were still deviant in subjects with mild hearing impairment, although they improved significantly after level adjustment. Scores on the sentences-in-noise test were an exception: after correcting the presentation level, scores of the hearing-impaired subjects were within normal limits.

Some authors have concluded that hearing loss has only a slight influence on dichotic-digit tests and pattern-recognition tests (Speaks et al, 1985; Musiek and Pinheiro, 1987; Musiek et al, 1990). However, our results do not support these findings: the hearing-impaired subjects in the present study did not show normal scores on these two tests. Some remarks should be made about this contradiction. First, a significant group difference was present on the dichoticdigit test, left ear score. Speaks et al (1985) suggested that dichotic-digit test results were minimally affected by hearing impairment, but they could not establish group differences because they lacked a control group with normal hearing. Second, some differences in cutoff scores on the pattern-recognition tests might explain the contradiction with the present results. Our cutoff scores $(77 \%$ in frequency patterns, $83 \%$ in duration patterns) were higher than those from Musiek and Pinheiro (1987; 75\% and $70 \%$, respectively), resulting in a higher percentage of abnormal scores. However, if we would apply Musiek's norms to our hearing-impaired subjects'scores, there still 
are several subjects who scored abnormal ( $42 \%$ and $17 \%$, respectively).

It should be noted that, regarding types of hearing loss, the present subject group is less heterogeneous than those of the abovementioned studies. The present study only included subjects with relatively flat, symmetrical hearing loss, whereas the other studies included both flat and sloping hearing loss. The influence of high-frequency hearing loss on test scores might be different from that of relatively flat hearing loss. Further research on test results in subjects with highfrequency hearing loss should gain insight into the influence of type of hearing loss on auditory processing test results.

In conclusion, although there were some methodological differences, the present results on the dichotic-digit test and patternrecognition tests do not support the results of earlier studies.

\section{Compensating for the Hearing Loss by Adjusting the Presentation Level}

Although some authors suggest that the assessment of APD in hearing-impaired subjects should be based on careful examination of (peripheral) audiometrical data and/or ear differences in auditory processing test scores (Miltenberger et al, 1978; Musiek and Lamb, 1994), we have hypothesized that auditory processing tests could be administered to patients with mild hearing impairment, provided that the audibility of stimuli is sufficient. In the dichotic-digit test and pattern-recognition tests, audibility was considered to be sufficient at the standard presentation level. In the sentences-in-noise, words-in-noise, filtered-speech, and binaural-fusion tests, audibility was increased by correcting the presentation level. The only test in which the hearing-impaired subjects showed optimal benefit from this correction was the sentences-in-noise test, especially in the fluctuating noise condition. A possible explanation is that the speech that occurred in the relatively quiet periods became more audible and thus improved the scores. The deviant scores on the remaining five tests showed that increasing audibility was not enough to account for even mild hearing impairment. Although Miltenberger et al (1978) found that 54 out of 70 hearing- impaired subjects failed one or more auditory processing tests, they explained this high percentage of failure as a result of not carefully examining audiometric data, like speech discrimination scores and asymmetries. They stated that in most cases, audiometric data alone could predict the results of auditory processing tests. In contrast, all the subjects in the present study had symmetrical hearing loss, and their word-recognition scores corresponded with the pure-tone hearing thresholds. Nevertheless, despite this correspondence, the results cannot be explained on the basis of audiometric data. Furthermore, although significant correlations were shown between word-recognition scores in quiet and several auditory processing test scores, these correlations did not apply to pure-tone and speech thresholds.

The lack of correlation between auditory processing test scores and measures for audibility suggests not only that audibility plays a role in mild hearing loss of up to $45 \mathrm{~dB}$ but that there are additional perception problems at suprathreshold level. This supports the findings of Bamford and Saunders, who reported: "Pure-tone sensitivity predicts 'sensitivity loss' for speech (SRT) quite well; but it does not account for more than about a quarter of the variability of speechdiscrimination scores" (1991, p. 105). Needleman and Crandell (1995) found that there was a lack of correlation between speech-discrimination scores and hearing thresholds in hearing-impaired subjects; this was confirmed in the present study. Other authors found that besides the loss of audibility, there was also a loss of temporal resolution capacity (Stuart and Phillips, 1998), as well as decreased ability to use dynamic spectral information (Plyler and Hedrick, 2002). Recently, Baker and Rosen (2002) have shown that loss of frequency selectivity is present even in the mildest hearing loss $(>25 \mathrm{~dB})$. Thus, additional perception problems need to be taken into account when administering auditory processing tests to mildly hearingimpaired patients. Analyses showed that for the words-in-noise, filtered-speech, and binaural-fusion tests, an additional correction factor could be useful. However, the scores on the dichotic-digit test and 
pattern-recognition tests could not be corrected in a similar way and therefore remained deviant.

\section{CONCLUSION}

$\mathrm{E}_{\mathrm{a}}^{\mathrm{v}}$ ven mild sensorineural hearing loss had a detrimental effect on auditory processing test scores, despite adjusting the presentation level for loss of audibility.

Therefore, it is not advisable to make straightforward comparisons between auditory processing test results from patients with hearing impairment and normative data from control subjects with normal hearing. The effects of hearing loss cannot be separated from auditory processing (dis)abilities. On the other hand, by using various adaptations, such as adjusting the presentation level and applying additional correction methods, the effect of subnormal hearing might be minimized. Nevertheless, the present dichotic-digit test and patternrecognition test still proved to be unsuitable for detecting auditory processing disorders in mildly hearing-impaired subjects.

\section{REFERENCES}

ASHA. (1996). Central auditory processing: current research and implications for clinical practice. Am J Audiol 5:41-54.

Baker RJ, Rosen S. (2002). Auditory filter nonlinearity in mild/moderate hearing impairment. JAcoust Soc Am 111:1330-1339.

Bamford J, Saunders E. (1991). Auditory perception in sensorineural hearing loss. In: Hearing Impairment, Auditory Perception and Language Disability. London: Whurr Publishers, 82-117.

Bellis TJ. (1996). Assessment and Management of Central Auditory Processing Disorders in the Educational Setting: From Science to Practice. San Diego: Singular Publishing.

Bornstein SP, Wilson RH, Cambron NK. (1994). Lowand high-pass filtered Northwestern University Auditory Test No. 6 for monaural and binaural evaluation. J Amer Acad Audiol 5:259-264.

Bosman AJ. (1989). Speech Perception by the Hearing Impaired. Utrecht: University of Utrecht.

Bosman AJ, Smoorenburg GF. (1992). Woordenlijst voor spraakaudiometrie. Electro Medical Instruments bv and Veenhuis Medical Audio bv, Gouda, the Netherlands. Compact disc.
Chermak GD, Musiek FE. (1997). Central Auditory Processing Disorders; New Perspectives. San Diego: Singular Publishing Group.

Fifer RC, Jerger JF, Berlin CI, Tobey EA, Campbell JC. (1983). Development of a dichotic sentence identification test for hearing-impaired adults. Ear Hear 4:300-305.

Jerger J, Musiek F. (2000). Report of the consensus conference on the diagnosis of auditory processing disorders in school-aged children. J Am Acad Audiol 11:467-474.

Keith RW. (2000). Development and standardization of scan-c test for auditory processing disorders in children. J Am Acad Audiol 11:438-445.

Kimura D. (1961). Some effects of temporal lobe damage on auditory perception. Can J Psychol 15:156-165.

Matzker J. (1959). Two new methods for the assessment of central auditory functions in case of brain disease. Ann ORL 68:1185-1197.

Max L. (1995). Betrouwbaarheid van een nederlandstalige dichotische luistertest met cijfers. Tijdschrift voor Stem-Spraak- en Taalpathologie 4:115-131.

Max L, D'Haese P. (1994). Digitale realisatie van een nederlandstalige dichotische luistertest met cijfers. Tijdschrift voor logopedie en audiologie 24:36-41.

Miltenberger G, Dawson G, Raica A. (1978). Central auditory testing with peripheral hearing loss. Arch Otolaryngol 104:11-15.

Moore BC. (1996). Perceptual consequences of cochlear hearing loss and their implications for the design of hearing aids. Ear Hear 17:133-161.

Musiek FE. (1994). Frequency (pitch) and duration pattern tests. J Am Acad Audiol 5:265-268.

Musiek FE. (1999). Central auditory tests. Scand Audiol 28(suppl. 51):33-46.

Musiek FE, Baran JA, Pinheiro ML. (1990). Duration pattern recognition in normal subjects and patients with cerebral and cochlear lesions. Audiology 29:304-313.

Musiek FE, Lamb L. (1994). Central auditory assessment: an overview. In: Katz J, ed. Handbook of Clinical Audiology. Baltimore: Williams and Wilkins, 197-211.

Musiek FE, Pinheiro ML. (1987). Frequency patterns in cochlear, brainstem, and cerebral lesions. Audiology 26:79-88.

Needleman AR, Crandell CC. (1995). Speech recognition in noise by hearing-impaired and noise-masked normal-hearing listeners. J Am Acad Audiol 6:414-424.

Neijenhuis KA, Snik A, van den Broek P. (in press). Auditory processing disorders in adults and children; evaluation of a test battery. Int $J$ Audiol.

Neijenhuis KA, Stollman MH, Snik AF, Van den Broek P. (2001). Development of a central auditory test battery for adults. Audiology 40:69-77. 
Noffsinger D, Wilson RH, Musiek FE. (1994). Department of veterans affairs compact disc recording for auditory perceptual assessment: background and introduction. J Am Acad Audiol 5:231-235.

Pinheiro ML, Ptacek PH. (1971). Reversals in the perception of noise and tone patterns. J Acoust Soc Amer 49:1778-1783.

Plomp R, Mimpen AM. (1979). Improving the reliability of testing the speech reception threshold for sentences. Audiology 18:43-52.

Plyler PN, Hedrick MS.(2002). Effects of stimulus presentation level on stop consonant identification in normal-hearing and hearing-impaired listeners. $J$ Amer Acad Audiol 13:154-159.

Schwartz DM, Lyregaard PE, Lundh P. (1988). Hearing aid selection for severe-to-profound hearing loss. Hear J 41:13-17.

Speaks C, Niccum N, Van Tasell D. (1985). Effects of stimulus material on the dichotic listening performance of patients with sensorineural hearing loss. $J$ Sp Hear Res 28:16-25.

Stuart A, Phillips DP. (1998). Recognition of temporally distorted words by listeners with and without a simulated hearing loss. J Am Acad Audiol 9:199-208. 